\title{
Nacer Khelouz, Les écrivains algérianistes et arabo- berbères face à la France coloniale
}

\section{Claudia Mansueto}

\section{(2) OpenEdition}

1 Journals

\section{Édition électronique}

URL : http://journals.openedition.org/studifrancesi/3893

DOI : 10.4000/studifrancesi.3893

ISSN : 2427-5856

Éditeur

Rosenberg \& Sellier

\section{Édition imprimée}

Date de publication : 1 décembre 2012

Pagination : 619

ISSN : 0039-2944

\section{Référence électronique}

Claudia Mansueto, « Nacer Khelouz, Les écrivains algérianistes et arabo-berbères face à la France coloniale », Studi Francesi [En ligne], 168 (LVI | III) | 2012, mis en ligne le 30 novembre 2015, consulté le 06 mars 2021. URL : http://journals.openedition.org/studifrancesi/3893 ; DOI : https://doi.org/ 10.4000/studifrancesi.3893

Ce document a été généré automatiquement le 6 mars 2021.

\section{(c)}

Studi Francesi è distribuita con Licenza Creative Commons Attribuzione - Non commerciale - Non opere derivate 4.0 Internazionale. 


\title{
Nacer Khelouz, Les écrivains algérianistes et arabo-berbères face à la France coloniale
}

\author{
Claudia Mansueto
}

\section{RÉFÉRENCE}

NACER KHELOUZ, Les écrivains algérianistes et arabo-berbères face à la France coloniale, «The French Review», n. 1, vol. 85, 2011, pp. 128-141.

1 Ce numéro comprend sept sections: «L'Année littéraire» qui vise à analyser les aspects culturels les plus représentatifs de l'année 2010; «Focus on the classroom» qui réfléchit sur les finalités pédagogiques du film Bienvenue chez les Ch'tis; «Film» qui présente au grand public la pellicule Mon colonel (2006); «Literature» qui propose des articles finalisés à la connaissance d'intellectuels de frontière, voix cryptiques qui refusent toute forme de classification généraliste; «Interview» (pp.144-154) qui comprend un entretien de Martine MOTARD-NOAR avec Sylvie Gracia, interprète raffinée du «brouillard contemporain des passions» (p. 152); «Lettrismes» (pp. 155-158) qui inclut l'étude de Serge ABRATE Danse et musique en politique et «Reviews» (pp.159-230) qui présente au lecteur les dernières parutions littéraires.

2 «L'Année littéraire» comprend les articles de Stéphane SPOIDEN Bloc-notes culturel: l'année de tous les scandales (pp. 14-29), d'Edward BARON TURK Avignon 2010: Celebrating the BodySingular and Collective (pp. 30-41), d'Aaron PREVOTS The Year in Poetry 2010: from Bonnefoy to the Blues (pp. 42-56) et de William CloonAN History and histoire: the Novel in 2010 (pp. 57-73); «Focus on the classroom» inclut l'article de Nathalie DEGROULT Bienvenue chez les Ch'tis: approche pédagogique d'un film de ch'nord (pp. 76-90); «Film» présente l'article de Nicole Beth WALLENBROCK Awakening from the Algerian war: Mon colonel (pp.92-100); «Literature» comprend les études d'Irina DZERO Meanings of Hybridity in Aimé Césaire's Discours sur le colonialisme (pp. 102-114), de Carolyn A. DURHAM Optimal Adaptation in Fred 
Vargas's and Régis Wargnier's Pars vite et reviens tard (pp. 115-127) et de Nacer KHELOUZ Les écrivains algérianistes et arabo-berbères face à la France coloniale (pp. 128-141).

Parmi les trois articles qui composent la section «Literature», on a choisi d'analyser celui de Nacer Khelouz Les écrivains algérianistes et arabo-berbères face à la France coloniale. Khelouz concentre son attention sur l'essai coécrit par Gilles Deleuze et Félix Guattari Kafka, pour une littérature mineure (1975) afin de réfléchir sur les caractéristiques de la naissante littérature algérienne francophone pendant la période coloniale. Observateurs de la «babélisation» (p. 131) nationale, les intellectuels de l'Algérie in fieri expriment «la raréfaction du mot» (p. 132), le triomphe du bruit sur le signifiant. Dans son étude, Khelouz met en évidence l'originalité de la production algérienne: si Deleuze et Guattari soulignaient la valeur collective de toute littérature mineure, Khelouz constate le profond isolement de l'intellectuel algérien francophone. Interprète original de la complexe situation culturelle pendant la domination européenne, Khelouz souligne la dissidence comportementale de l'écrivain algérien: porte-parole de sa solitude, l'auteur francophone narre son «exil individuel» (p. 140).

4 En conclusion, l'étude de Khelouz montre au lecteur l'inutilité de toute forme de catégorisation littéraire. L'analyse du panorama culturel francophone colonial dénonce la faiblesse des coordonnées présentées par Deleuze et Guattari: le cas algérien contredit les considérations des auteurs de l'essai Kafka pour une littérature mineure et met en évidence l'intime anticonformisme d'une littérature problématique qui revendique son unicité. 